Acta Sci. Pol. Technol. Aliment. 19(1) 2020, 5-14

pISSN 1644-0730

eISSN 1898-9594

http://dx.doi.org/10.17306/J.AFS.2020.0733

ORIGINAL PAPER

Received: 21.10 .2019

Accepted: 30.12.2019

\title{
OPTIMIZATION OF THE ULTRASOUND-ASSISTED EXTRACTION OF POLYPHENOL, MANGIFERIN, AND ITS ANTIOXIDANT EXPRESSION IN MANGO PEEL (MANGIFERA INDICA) USING RESPONSE SURFACE METHODOLOGY
}

\author{
Marcela Morales ${ }^{1 \bowtie}$, Karol Zapata ${ }^{2}$, Carlos A. Sagaste ${ }^{3}$, Alberto A. Angulo , \\ Benjamín Rojano ${ }^{1}$ \\ 'Laboratorio de Ciencias de los Alimentos, Facultad de Ciencias, Universidad Nacional de Colombia \\ Carrera 65 \# 59a - 110, Medellín, Antioquia, Colombia \\ ${ }^{2}$ Departamento de Procesos y Energía, Facultad de Minas, Universidad Nacional de Colombia \\ Medellín, Colombia \\ Instituto de Ingeniería, Universidad Autónoma de Baja California \\ Blvd. Benito Juárez, Insurgentes Este, 21280 Mexicali, Mexico \\ ${ }^{4}$ Departamento de Química, Facultad de Ciencias Básicas, Universidad de Córdoba \\ Montería, Colombia
}

\begin{abstract}
Background. Emerging extraction techniques for bioactive compounds have been cataloged as efficient and cost effective compared to conventional ones. The objective of this research was to define the time and temperature that will guarantee a higher mangiferin content and antioxidant potential in Colombian Criollo mango peel through Ultrasound Assisted Extraction (UAE).

Materials and methods. To find the optimal extraction conditions, response surface methodology was used, proposing a $3^{2}$ factorial experimental design having as response variables the content of mangiferin and total phenols, and the antioxidant activity measured through ABTS and ORAC techniques.

Results. According to the results obtained, the $R^{2}$ values were in accordance with the adjusted $R^{2}$ values, showing that the data fit the model well. The results showed that both time and temperature had a significant effect on all the variables evaluated $(p<0.05)$. The optimization of multiple responses showed that the optimal extraction conditions were $10 \mathrm{~min}$ and $54^{\circ} \mathrm{C}$; these values were performed experimentally to compare theoretical values, finding percentages of standard residual error of less than $5 \%$.

Conclusion. This allows the conclusion that the optimal parameters of temperature and time in ultrasoundassisted extraction were defined in Criollo mango peel. On the other hand, the peel showed a considerable metabolite content and antioxidant activity, suggesting it as a possible functional additive in the production of juices, nectars, and other mango-based products.
\end{abstract}

Keywords: ultrasound-assisted extraction, antioxidant activity, optimization, response surface, mango

Source of financing: Fellowship Joven Investigador of Colciencias.

『dimmoralessav@unal.edu.co, phone +57 4430 9381, +57 3022065182 


\section{INTRODUCTION}

Mango is one of the most important tropical fruits in the world, whose uses range from products such as puree, nectar, and juices to leather, pickles and canned slices (Loelillet, 1994). The peel is a byproduct of mango processing that is not used for any commercial purpose, but is discarded and becomes a source of contamination; for example, in Colombia, $40 \%$ of the weight of the mango corresponds to the peel and the seed, which means that, of the tons of fruit generated in a year, 105,854 are waste (Serna and Torres, 2015). However, several authors have proposed it as a rich source of polyphenols, anthocyanins and carotenoids that also exhibits a good antioxidant activity by effectively scavenging several free radicals, such as DPPH, hydroxyl radical and peroxyl radical, and by reducing ferric ion to ferrous ion (Ajila et al., 2007; Masibo and $\mathrm{He}, 2009$ ). Within this wide variety of bioactive compounds, there is mangiferin, a xanthone that has attracted attention due to its various biological activities, such as antiviral, anticancer, antidiabetic, immunomodulatory, hepatoprotective and analgesic, all attributed primarily to its antioxidant capacity (Barreto et al., 2008; Muruganandan et al., 2005; Noratto et al., 2010).

The extraction of these bioactive compounds has been studied extensively in different matrices. Commonly, classical techniques based on choosing a solvent in combination with stirring and/or heat, such as the Soxhlet method, and maceration have been used (González-Quijano et al., 2019). However, these traditional methods require a long time and relatively large amounts of solvent, causing a possible negative effect on the activity of these compounds and generating significant waste (Dorta et al., 2012). That is why emerging extraction methods have been proposed which seek to improve efficiency, reduce operating times and solvent consumption (González-Quijano et al., 2019; Ruiz-Montañez et al., 2014).

Among these, Ultrasound Assisted Extraction (UAE) is considered an efficient extraction method due to the effects of the ultrasound wave, which produces acoustic cavitations in the solvent. The ultrasound also has a mechanical effect that allows a greater penetration of solvent into the tissue, increasing the contact surface area between the solid phase and the liquid phase. Finally, the solute diffuses rapidly from the solid phase to the solvent (Ghafoor et al., 2009; Rostagno et al., 2003; Zou et al., 2013).

On the other hand, the extraction of bioactive compounds from the mango peel can be affected by more than one factor, such as the extraction solvent, temperature, time, solid-liquid ratio, etc. The response surface methodology (RSM) is an effective technique to analyze interactions between factors and their relationship with the response variables, and for the optimization of extractive processes where multiple parameters can influence the results (Zou et al., 2013). In the literature, there are few reports on the extraction of mangiferin in the mango peel; most have concentrated on studying the leaves. Therefore, this research aimed to optimize the extraction parameters (time and temperature) through four response variables (Total Phenols, Mangiferin, ABTS and ORAC) through the application of RSM.

\section{MATERIALS AND METHODS}

\section{Materials}

Mangoes of the Criollo variety were bought from Montería, Córdoba (18 MASL and $28^{\circ} \mathrm{C}$ average temperature in April 2017) and were stored at $-20^{\circ} \mathrm{C}$. Copies were randomly collected in a mature state under optimal conditions. Ethanol and other solvents were purchased from Fisher Scientific Co. (Fair Lawn, NJ, USA); 2,2'-Azinobis (2-amidinopropane) hydrochloride (AAPH), fluorescein, Trolox ${ }^{\circledR}$, were purchased from Sigma-Aldrich Chem.Co (Millwakee, WI). Ultraviolet-visible measurements were performed on a Multiskan Spectrum (Thermo Scientific) spectrophotometer. The decrease in fluorescence intensity measured in the ORAC assay was performed in a Perkin-Elmer LS-55 Spectrofluorometer (U.K.).

\section{Sample preparation}

The mangoes in a mature state were selected according to their physical state, without deterioration or bruises, for subsequent disinfection. Then, they were manually pulped. The peel obtained was lyophilized $\left(-18^{\circ} \mathrm{C}-\right.$ $5 \mathrm{~Pa}$ ) and then pulverized using a fruit chopper. The powder was homogenized with the solvent in Ultratur$\operatorname{rax}{ }^{\circledR}$ at $10,000 \mathrm{rpm}$ and deposited in glass flasks which were covered with sticky paper. This preparation was done 18 times (number of experiments performed). 


\section{Determination of total phenols, mangiferin, ABTS and ORAC}

The phenolic determination was carried out using the Folin-Ciocalteu colorimetric method designed by Singleton and Rosi (1965). The results were expressed as mg of Equivalent Gallic Acid: GAE/100 g dry matter (lyophilized). Measurement of the mangiferin content was performed using liquid chromatography (Shimad$\mathrm{zu}{ }^{\circledR} \mathrm{LC}-20 \mathrm{AD} / \mathrm{T}$ HPLC equipped with an SPD 6AUV detector (Kyoto, Japan), equipped with an auto-injector and a photodiode matrix detector (PDA) and a C18 column (5 microns) $250 \times 4.6 \mathrm{~mm}$ (Restek ${ }^{\circledR}$, Bellefonte, USA) as the stationary phase) according to the protocol proposed by Schieber et al. (2000) with some modifications. The results were expressed as mg of manguiferin / $100 \mathrm{~g}$ lyophilized. The ABTS and ORAC methodologies were performed according to the method proposed by Prior et al. (2005) and Romero et al. (2010), respectively. The results were expressed as TEAC values (Trolox Equivalent Antioxidant Capacity).

\section{Selection of relevant variables and experimental ranges}

The independent variables that were optimized were the extraction time and temperature, because they are the parameters that most influence the extractive processes (Ghafoor et al., 2009; Su et al., 2006). To define the working range of the design factors, previous trials were carried out where it was found that times of less than 10 minutes had no effect on the response variables (data not reported) and extraction times greater than 70 minutes are inefficient in extractions assisted by ultrasound (Zou et al., 2014). Regarding the temperature range, it was established according to previously reported studies on polyphenol extractions, which show that temperatures above $70^{\circ} \mathrm{C}$ cause a high deterioration in antioxidant metabolites (Forero and Pulido, 2016; Kim et al., 2010).

On the other hand, other extraction variables were chosen based on the literature: Ethanol-Water solvent $40 \%$ in relation to $1: 30$ (solute : solvent; Kulkarni and Rathod, 2016; Prasad et al., 2011; Zou et al., 2013; 2014).

\section{Experimental design}

A $3^{2}$ factorial experimental design was proposed using Statgraphics Centurion XVI software, as shown in
Table 1, in order to determine the best combination of the extraction factors for phenolic compounds, mangiferin and its antioxidant expression in mango peel. The order of the experiments was totally random. The factors and their levels are described in Table 2.

Table 1. Experimental design

\begin{tabular}{ccc}
\hline Experiment & Time, $\min$ & Temperature, ${ }^{\circ} \mathrm{C}$ \\
\hline 1 & 70 & 70 \\
2 & 40 & 30 \\
3 & 10 & 50 \\
4 & 10 & 30 \\
5 & 40 & 50 \\
6 & 70 & 30 \\
7 & 40 & 70 \\
8 & 10 & 70 \\
9 & 70 & 50 \\
\hline
\end{tabular}

Table 2. Definition of variables for factorial design

\begin{tabular}{lcc}
\hline \multicolumn{1}{c}{ Factor } & Levels & Response variables \\
\hline Time, min & 10 & \\
& 40 & \\
& 70 & ABTS \\
& 30 & ORAC \\
Temperature, ${ }^{\circ} \mathrm{C}$ & 50 & matal phenols \\
& 70 & \\
\hline
\end{tabular}

A second order polynomial equation was used to express the responses based on independent variables and three-dimensional graphs of the response surface were generated by oscillating two variables within the experimental range.

\section{Data analysis}

The results were analyzed using the "Response Surface" methodology, a set of mathematical and statistical techniques used to model and analyze problems, with the objective of determining the optimal operating 
conditions of a system (Silva, 2012). For this, Statgraphics Centurion XVI software was used again, highlighting that the quality of the adjustment of the equation of the polynomial model was expressed by the regression coefficient $R^{2}$, and its meaning was verified by the value $p$.

\section{Determination of optimal conditions for extraction and verification of the model}

The optimal extraction conditions are found using the tool "Optimization of multiple responses" through Statgraphics Centurion XVI software, looking for an optimum desirability of the response variables, that is, the maximum value of total phenols, mangiferin, ABTS and ORAC. Verification of the validity and adequacy of the predictive extraction model was performed under optimal conditions of time and temperature. Three experimental repetitions were performed under these optimized conditions and the experimental values were compared with the predicted ones.
The percentage of the standard residual error (SRE) was calculated for each response.

\section{RESULTS AND DISCUSSION}

\section{Fit to model}

The experimental content of total phenols, mangiferin, and the antioxidant activity ABTS and ORAC of the peel extracts were used to calculate the coefficients of the second order polynomial equation, regression coefficients and $p$-values (Table 3 ). According to the results, the $R$-square values are in accordance with the adjusted $R$-square values, which indicates a good adaptation to the model and a linear relationship between experimental and predicted data. On the other hand, bioactive metabolites (total phenols and mangiferin) and antioxidant activity (ABTS and ORAC) were significantly affected by the time and temperature of the extraction $(p<0.05)$.

Table 3. Polynomial equation and statistical parameters calculated after the implementation of the $3^{2}$ factorial experimental design

\begin{tabular}{|c|c|c|c|c|c|}
\hline \multirow{2}{*}{$\begin{array}{l}\text { Response } \\
\text { variable }\end{array}$} & \multirow{2}{*}{$\begin{array}{c}\text { 2nd order polynomial } \\
\text { equation }\end{array}$} & & & \multicolumn{2}{|c|}{$p$ value } \\
\hline & & & & time & temperature \\
\hline ABTS & $\begin{array}{c}13152.1+60.7007 \times t \\
+1319,61 \times{ }^{\circ} \mathrm{T} \\
-0.0327815 \times t^{2} \\
-4.0778 \times t \times{ }^{\circ} \mathrm{T} \\
-10.1832 \times{ }^{\circ} T^{2}\end{array}$ & 0.94 & 0.91 & 0.000 & 0.0000 \\
\hline $\begin{array}{l}\text { Total } \\
\text { phenols }\end{array}$ & $\begin{array}{c}719.974+13.6452 \times t \\
+108.841 \times{ }^{\circ} T \\
-0.122754 \times t^{2} \\
-0.194735 \times t \times{ }^{\circ} T \\
1.04741 \times{ }^{\circ} T^{2}\end{array}$ & 0.96 & 0.94 & 0.000 & 0.030 \\
\hline Mangiferin & $\begin{array}{c}99.8073+0.877525 \times t \\
+8.5055 \times{ }^{\circ} \mathrm{T} \\
-0.00126204 \times t^{2} \\
-0.0223896 \times t \times{ }^{\circ} \mathrm{T} \\
-0.0808271 \times{ }^{\circ} T^{2}\end{array}$ & 0.95 & 0.93 & 0.000 & 0.0001 \\
\hline ORAC & $\begin{array}{c}-6121.15+109.927 \times t \\
+1077.86 \times{ }^{\circ} \mathrm{T} \\
+0.228731 \times t^{2} \\
-3.38349 \times t \times{ }^{\circ} \mathrm{T} \\
-10.9423 \times{ }^{\circ} T^{2}\end{array}$ & 0.98 & 0.97 & 0.000 & 0.000 \\
\hline
\end{tabular}




\section{Response surface analysis}

The response surface graphs obtained for the variables studied are shown below.

Effect of temperature on the content of antioxidant metabolites and their activity. Most authors agree that increasing the working temperature favors extraction, improving solute solubility and diffusion coefficient. However, above a certain value, phenolic compounds can be degraded (Prasad et al., 2009; Spigno and De Faveri, 2007). In this work, it was observed that above $60^{\circ} \mathrm{C}$ (Fig. 1) the metabolite content and antioxidant activity began to decrease. A similar behavior was reported by Dorta et al. (2012) in mango skin, who found that the extraction of polyphenols improved by increasing the temperature from $25^{\circ} \mathrm{C}$ to $60^{\circ} \mathrm{C}$ using aqueous solvents. Mokrani and Madani (2016) reported that above $60^{\circ} \mathrm{C}$ they obtained a decrease in the content of total phenols extracted from the fruit of Prunus persica L. Regarding the content of mangiferin, optimal extraction values around $60^{\circ} \mathrm{C}$ have also been reported (Prasad et al., 2011; Zou et al., 2014). The increase in secondary metabolites, such as mangiferin and total phenols, could be explained because the heating softens the plant tissue and weakens the interactions between the phenolic compounds bound to proteins and polysaccharides and, therefore, there would be greater migration to the solvent (García-Salas et al., 2010; Wang et al., 2006). On the other hand, chemical and enzymatic decomposition and losses due to volatilization or thermal decomposition have been suggested as main mechanisms for reducing antioxidant metabolites at high temperatures (Soong et al., 2004).

In relation to antioxidant activity, a similar behavior was observed. At temperatures above $50^{\circ} \mathrm{C}$ the antioxidant capacity measured through the ABTS and ORAC methodologies decreased (Fig. 1). According to García-Márquez et al. (2012) this behavior could be due to a principle of equilibrium, in which high temperatures can increase the extraction speed and allow
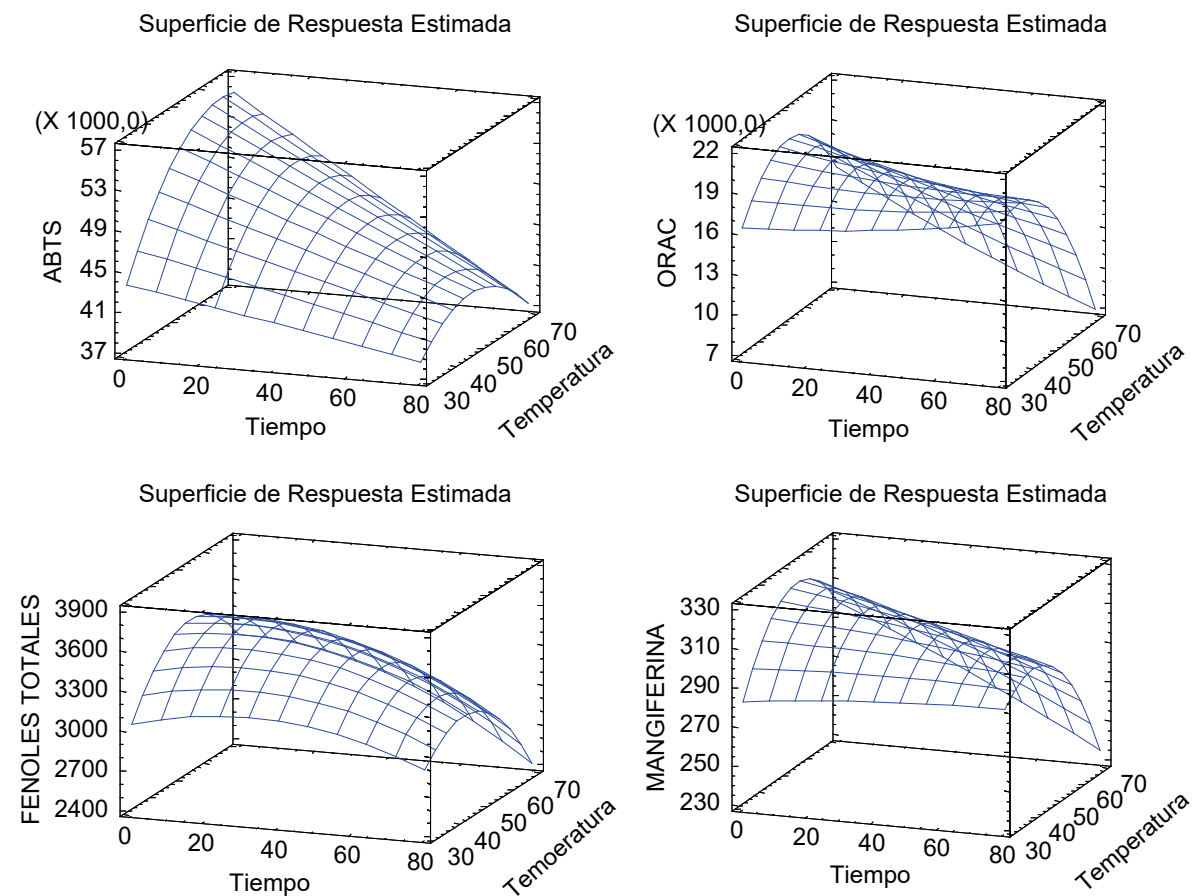

Fig. 1. Response surfaces of metabolites and antioxidant activity of mango peel affected by time and extraction temperature in UAE: A - ABTS, $\mu$ mol Trolox/100 g lyophilized; $\mathrm{B}$ - ORAC, $\mu \mathrm{mol}$ Trolox/100 g lyophilized; C - total phenols, GAE mg/100 g lyophilized; $\mathrm{D}$ - mangiferin, $\mathrm{mg} / 100 \mathrm{~g}$ lyophilized 
a maximum recovery of the content of phenolic compounds and, thus, a higher content of antioxidant compounds. However, very high temperatures may not be suitable for all types of phenolic compounds.

Effect of time on the content of antioxidant metabolites and their activity. The time during which the extraction solvent and the matrix are in contact influences the progressive release of the metabolites and the efficiency of the extraction. The results of this work coincide with those reported in the literature, since it was found that desirable yields of antioxidant metabolites were obtained in a short time (Fig. 1) compared with extractions performed by conventional methods such as Soxhlet (Ruiz-Montañez et al., 2014; Wang and Weller, 2006).

In different studies, a good correlation between phenol content and antioxidant activity was also observed using UAE in extractions performed on other fruit (Ghafoor et al., 2009; Su and Silva, 2006), and it was also concluded that the time and temperature extraction variables strongly influenced the antioxidant profile evaluated after applying UAE.

\section{Experimental determination and validation of optimal extraction conditions}

The estimated levels of optimal extraction conditions for the maximum response of total phenols, mangiferin and antioxidant activity (ABTS and ORAC) of mango peel extract by UAE are summarized in Table 4 .

The prediction of the set of optimal conditions for the four response variables was made by using the desirability function. A total desirability value of 0.93 was obtained on a scale of 0 to 1 , where 0 represents a completely undesirable response and 1 represents the most desirable response.

To confirm these results, the experiments were carried out under the conditions optimized in triplicate, obtaining results very close to those predicted (Table 5).

The results were compared with the predicted values by calculating the percentages of SRE (Eq. 1). According to Che Sulaiman et al. (2017) it was considered that SRE values below 5\% were in accordance with predicted values. As can be seen in Table 6, there were no significant differences between the predicted and experimental values, which allows the conclusion that these conditions are optimal for extraction.

Table 4. Optimum conditions for maximum extraction in mango peel

\begin{tabular}{lrccc}
\hline \multicolumn{1}{c}{$\begin{array}{c}\text { Response } \\
\text { variable }\end{array}$} & Optimum & Time, min & Temperature, ${ }^{\circ} \mathrm{C}$ & Desirability \\
\hline ABTS & 53070.5 & & & \\
Total phenols & 3568.7 & 10 & 54 & 0.93 \\
Mangiferin & 320.1 & & & \\
ORAC & 19506.6 & & & \\
\hline
\end{tabular}

Table 5. Predicted and experimental values for optimized peel extraction parameters

\begin{tabular}{lcccc}
\hline \multicolumn{1}{c}{ Values } & $\begin{array}{c}\text { Total phenols } \\
\text { mg GAE }\end{array}$ & $\begin{array}{c}\text { Mangiferin } \\
\mathrm{mg}\end{array}$ & $\begin{array}{c}\text { ABTS } \\
\mu \text { mol Trolox }\end{array}$ & $\begin{array}{c}\text { ORAC } \\
\mu \text { mol Trolox }\end{array}$ \\
\hline Predicted & 3568.70 & 316.86 & 53070.50 & 19506.60 \\
Experimental & 3601.78 & 314.34 & 53220.04 & 19250.67 \\
SRE, \% (eq. 1) & 0.93 & 0.80 & 0.28 & 1.31 \\
\hline
\end{tabular}

*All results are expressed per $100 \mathrm{~g}$ lyophilized. 


$$
\begin{aligned}
& \text { Standard } \\
& \text { residual error }
\end{aligned}=\frac{\text { Experimental }_{\text {value }}-\text { Predicted }_{\text {value }}}{\text { Predicted }_{\text {value }}} \cdot 100
$$

The optimum temperature found in this work was $54^{\circ} \mathrm{C}$. This coincides with the results obtained by different authors that optimized the extraction of antioxidants in other fruit, since there are very few reports of optimization of mango peel extraction (Ghafoor et al., 2009; Pinelo et al., 2005).

On the other hand, different authors have reported optimal extraction times of less than 1 hour, such as the one found in this investigation (Table 4), concluding that applying the ultrasound for longer may cause deterioration of the plant material as a result of the oxidation of the phenolic compounds. They have even suggested that 10-minute extractions allow a large proportion of flavonoid-type phenols to be obtained (Barreira et al., 2009; Rostagno et al., 2003). However, the optimal values are highly influenced by the plant matrix, since there are different degrees of phenolic polymerization, solubility of phenolic compounds and their interaction with other food components within the matrix, which leads to a difference in time to achieve a balance in the transfer of mass from the solid matrix to the solvent (Thoo et al., 2010).

\section{Percentage of influence of the factors on the response variables}

According to Table 6, variation of the parameters evaluated was mainly due to temperature. Commonly, temperature is considered one of the factors that most affects antioxidants in extractive processes, because it increases their solubility and, therefore, accelerates the mass transfer rate. In addition, the viscosity and surface tension of the solvents are lower at a higher

Table 6. Percentage of influence of the factors on the response variables in mango peel

\begin{tabular}{lcc}
\hline \multicolumn{1}{c}{ Factors } & Time, $\%$ & Temperature, \% \\
\hline ABTS & 39.25 & 60.75 \\
Phenols total & 11.85 & 88.15 \\
Mangiferin & 1.0 & 99.0 \\
ORAZ & 1.0 & 99.0 \\
\hline
\end{tabular}

temperature, helping them diffuse through the plant matrix in less time (Dai and Mumper, 2010; García-Salas et al., 2010).

\section{CONCLUSIONS}

The optimal conditions of extraction in criollo mango peel, of 10 minutes and $54^{\circ} \mathrm{C}$, were defined for a desirability of 0.93 . When evaluating the optimal conditions in peel, values of the total phenols and mangiferin content were found, as well as the ABTS and ORAC antioxidant activity, which were very close to the data predicted by the model. According to the above, it can be concluded that the ultrasonic extraction process in the mango peel was optimized.

The peel showed a considerable metabolite content and antioxidant activity suggesting it as a possible functional additive in the production of juices, nectars, or other mango-based products.

\section{REFERENCES}

Ajila, C., Bhat, S., Rao, P. (2007). Valuable components of raw and ripe peels from two Indian mango varieties. Food Chem., 102(4), 1006-1011. http://dx.doi. org/10.1016/j.foodchem.2006.06.036

Barreira, J. C. M., Ferreira, I. C. F. R., Oliveira, M. B. P. P., Pereira, J. A. (2009). Effects of different phenols extraction conditions on antioxidant activity of almond (Prunus dulcis) fruits. J. Food Biochem., 33(6), 763-776. http://dx.doi.org/10.1111/j.1745-4514.2009.00249.x

Barreto, J. C., Trevisan, M. T., Hull, W. E., Erben, G., de Brito, E. S., Pfundstein, B., ..., Owen, R. W. (2008). Characterization and quantitation of polyphenolic compounds in bark, kernel, leaves, and peel of mango (Mangifera indica L.). J. Agric. Food Chem., 5599-5610. http://dx.doi.org/10.1021/jf800738r

Che Sulaiman, I. S., Basri, M., Fard Masoumi, H. R., Chee, W. J., Ashari, S. E., Ismail, M. (2017). Effects of temperature, time, and solvent ratio on the extraction of phenolic compounds and the anti-radical activity of Clinacanthus nutans Lindau leaves by response surface methodology. Chem. Centr. J., 11(1), 54. http://dx.doi. org/10.1186/s13065-017-0285-1

Dai, J., Mumper, R. J. (2010). Plant phenolics: Extraction, analysis and their antioxidant and anticancer properties. Molecules, 15(10), 7313-7352. http://dx.doi. org/10.3390/molecules 15107313 
Morales, M., Zapata, K., Sagaste, C. A., Angulo, A. A., Rojano, B. (2020). Optimization of the ultrasound-assisted extraction of polyphenol, mangiferin, and its antioxidant expression in mango peel (Mangifera indica) using response surface methodology. Acta Sci. Pol. Technol. Aliment., 19(1), 5-14. http://dx.doi.org/10.17306/J.AFS.2020.0733

Dorta, E., Lobo, M. G., Gonzalez, M. (2012). Reutilization of mango byproducts: Study of the effect of extraction solvent and temperature on their antioxidant properties. J. Food Sci., 77(1), C80-C88. http://dx.doi.org/10.1111/ j.1750-3841.2011.02477.x

Forero, F., Pulido, A. P. (2016). Extracción, purificación y cuantificación de mangiferina en la corteza de algunos cultivares de mango (Mangifera indica L.). Rev. Colomb. Cien. Hort., 10(2), 292-300. http://dx.doi. org/10.17584/rcch.2016v10i2.4652

García-Márquez, E., Román-Guerrero, A., Pérez-Alonso, C., Cruz-Sosa, F., Jiménez-Alvarado, R., Vernon-Carter, E. J. (2012). Effect of solvent-temperature extraction conditions on the initial antioxidant activity and total phenolic content of muitle extracts and their decay upon storage at different pH. Rev. Mexic. Ing. Quím., 11(1), $1-10$.

Garcia-Salas, P., Morales-Soto, A., Segura-Carretero, A., Fernández-Gutiérrez, A. (2010). Phenolic-compoundextraction systems for fruit and vegetable samples. Molecules, 15(12), 8813-8826. http://dx.doi.org/10.3390/ molecules 15128813

Ghafoor, K., Choi, Y. H., Jeon, J. Y., Jo, I. H. (2009). Optimization of ultrasound-assisted extraction of phenolic compounds, antioxidants, and anthocyanins from grape (Vitis vinifera) seeds. J. Agric. Food Chem., 57, 49884994. http://dx.doi.org/10.1021/jf9001439

González-Quijano, G., Arrieta-Baez, D., Dorantes-Alvarez, L., Aparicio-Ozores, G., Guerrero-Legarreta, I. (2019). Effect of extraction method in the content of phytoestrogens and main phenolics in mesquite pod extracts (Prosopis sp.). Rev. Mexic. Ing. Quím., 18(1), 303-312. http://dx.doi.org/10.24275/uam/izt/dcbi/revmexing quim/2019v18n1/Gonzalez

Kim, W. J., Veriansyah, B., Lee, Y. W., Kim, J., Kim, J. D. (2010). Extraction of mangiferin from Mahkota Dewa (Phaleria macrocarpa) using subcritical water. J. Ind. Eng. Chem., 16(3), 425-430. http://dx.doi.org/10.1016/j. jiec.2009.08.008

Kulkarni, V., Rathod, V. (2016). Green process for extraction of mangiferin from Mangifera indica leaves. J. Biol. Activ. Prod. Nat., 6(5-6), 406-411. http://dx.doi.or g/10.1080/22311866.2016.1269615

Loelillet, D. (1994). The European mango market: A promising tropical fruit. Fruit, 49, 332-334.

Masibo, M., He, Q. (2009). Mango bioactive compounds and related nutraceutical properties - A review. Food Rev. Int., 25(4), 346-370. http://dx.doi.org/10.1080/ 87559120903153524
Mokrani, A., Madani, K. (2016). Effect of solvent, time and temperature on the extraction of phenolic compounds and antioxidant capacity of peach (Prunus persica L.) fruit. Separ. Purif. Technol., 162. http://dx.doi. org/10.1016/j.seppur.2016.01.043

Muruganandan, S., Srinivasan, K., Gupta, S., Gupta, P. K., Lal, J. (2005). Effect of mangiferin on hyperglycemia and atherogenicity in streptozotocin diabetic rats. J. Ethnopharm., 97, 497-501. http://dx.doi.org/10.1016/j. jep.2004.12.010

Noratto, G. D., Bertoldi, M. C., Krenek, K., Talcott, S. T., Stringheta, P. C., Mertens-Talcott, S. U. (2010). Anticarcinogenic effects of polyphenolics from mango (Mangifera indica) varieties. J. Agric. Food Chem., 58, 41044112. http://dx.doi.org/10.1021/jf903161g

Pinelo, M., Rubilar, M., Jerez, M., Sineiro, J., Núñez, M. J. (2005). Effect of solvent, temperature, and solvent-tosolid ratio on the total phenolic content and antiradical activity of extracts from different components of grape pomace. J. Agric. Food Chem., 53(6), 2111-2117. http:// dx.doi.org/10.1021/jf0488110

Prasad, K. N., Yang, E., Yi, C., Zhao, M., Jiang, Y. (2009). Effects of high pressure extraction on the extraction yield, total phenolic content and antioxidant activity of longan fruit pericarp. Inn. Food Sci. Emer. Technol., 10(2), 155-159. http://dx.doi.org/10.1016/j.ifset.2008.11.007

Prasad, K. N., Hassan, F. A., Yang, B., Kong, K. W., Ramanan, R. N., Azlan, A., Ismail, A. (2011). Response surface optimisation for the extraction of phenolic compounds and antioxidant capacities of underutilised Mangifera pajang Kosterm. peels. Food Chem., 128(4), 1121-1127. https://doi.org/10.1016/j.foodchem. 2011.03.105

Prior, R. L., Wu, X., Schaich, K. (2005). Standardized methods for the determination of antioxidant capacity and phenolics in foods and dietary supplements. J. Agric. Food Chem., 53(10), 4290-4302. http://dx.doi. org/10.1021/jf0502698

Romero, M., Rojano, B., Mella, J., Pessoa, C. D., Lissi, E., López, C. (2010). Antioxidant capacity of pure compounds and complex mixtures evaluated by the ORAC-Pyrogallol red assay in the presence of Triton X-100 micelles. Molecules, 15(9), 6152-6167. http://dx.doi. org/10.3390/molecules15096152

Rostagno, M. A., Palma, M., Barroso, C. G. (2003). Ultrasound-assisted extraction of soy isoflavones. J. Chromatogr., A, 1012(2), 119-128. http://dx.doi.org/10.1016/ S0021-9673(03)01184-1

Ruiz-Montañez, G., Ragazzo-Sánchez, J. A., Calderón-Santoyo, M., Velázquez-De La Cruz, G., Ramírez De 
León, J. A., Navarro-Ocaña, A. (2014). Evaluation of extraction methods for preparative scale obtention of mangiferin and lupeol from mango peels (Mangifera indica L.). Food Chem., 159(July), 267-272. http://dx.doi. org/10.1016/j.foodchem.2014.03.009

Schieber, A., Ullrich, W., Carle, R. (2000). Characterization of polyphenols in mango puree concentrate by HPLC with diode array and mass spectrometric detection. Inn. Food Sci. Emer. Technol., 1, 161-166. http://dx.doi. org/10.1016/S1466-8564(00)00015-1

Serna Cock, L., Torres León, C. (2015). Potencial agroindustrial de cáscaras de mango de las variedades Keitt, y Tommy Atkins (Mangifera indica). Acta Agron., 64, 110-115. http://dx.doi.org/10.15446/acag.v64n2.43579

Silva Chandía, S. (2012). Optimización del proceso de extracción supercrítica de los polifenoles de la vaina de tara (Caesalpinia spinosa). (Tesis de pregrado). Santiago de Chile: Universidad de Chile.

Singleton, V. L., Rossi, J. A. (1965). Colorimetry of total phenolics with phosphomolybdic-phosphotungstic acid reagents. Am. J. Enol. Viticult., 16, 144-158.

Spigno, G., De Faveri, D. M. (2007). Antioxidants from grape stalks and marc: influence of extraction procedure on yield, purity and antioxidant power of the extracts. J. Food Eng., 78, 793-801. http://dx.doi.org/10.1016/j. jfoodeng.2005.11.020

Soong, Y. Y., Barlow, P. J. (2004). Antioxidant activity and phenolic content of selected fruit seeds. Food Chem.,
88(3), 411-417. http://dx.doi.org/10.1016/j.foodchem. 2004.02.003

Su, M. S., Silva, J. L. (2006). Antioxidant activity, anthocyanins, and phenolics of rabbiteye blueberry (Vaccinium ashei) by-products as affected by fermentation. Food Chem., 97, 447-451. http://dx.doi.org/10.1016/j.foodchem.2005.05.023

Thoo, Y. Y., Ho, S. K., Liang, J. Y., Ho, C. W., Tan, C. P. (2010). Effects of binary solvent extraction system, extraction time and extraction temperature on phenolic antioxidants and antioxidant capacity from mengkudu (Morinda citrifolia). Food Chem., 120(1), 290-295. http://dx.doi.org/10.1016/j.foodchem.2009.09.064

Wang, L., Weller, C. L. (2006). Recent advances in extraction of nutraceuticals from plants. Trends Food Sci. Technol., 17(6), 300-312. http://dx.doi.org/10.1016/j. tifs.2005.12.004

Zou, T. B., Jia, Q., Li, H. W., Wang, C. X., Wu, H. F. (2013). Response surface methodology for ultrasound-assisted extraction of astaxanthin from Haematococcus pluvialis. Mar. Drugs, 11, 1644-1655. http://dx.doi.org/10.3390/ md11051644

Zou, T.-B., Xia, E.-Q., He, T.-P., Huang, M.-Y., Jia, Q., Li, H.-W. (2014). Ultrasound-assisted extraction of mangiferin from mango (Mangifera indica L.) leaves using response surface methodology. Molecules, 19(2), 14111421. http://dx.doi.org/10.3390/molecules19021411 